\title{
Views of teachers' and students' regarding the distribution of subjects in phase II and phase III of MBBS course
}

\author{
Brig Gen Dr. Md. Mohibur Rahman ${ }^{\prime}$, Professor Dr. Md. Humayun Kabir Talukder ${ }^{2}$
}

\begin{abstract}
This descriptive type of cross sectional study was conducted in twelve medical colleges of Bangladesh to assess the views of teachers and students regarding the distribution of subjects in Phase II and Phase III of MBBS curriculum 2012. This study was conducted from July 2017 to Apr 2018 where views were collected from 91 teachers and 991 students. Study revealed that, $90.1 \%$ respondents mentioned for rearrangement of subjects and around $87.9 \%$ teachers and $90.3 \%$ students opined for addition of Pathology subjects in Phase II of MBBS course. Study also recommended that more extensive study is needed to get an unanimous opinion from the students and medical teachers regarding the subjects in Phase II and Phase III of MBBS course.
\end{abstract}

Keywords: MBBS curriculum, Phase II, Phase III, para-clinical subjects, preclinical subjects

\section{Introduction}

The process of medical education in Bangladesh began with the establishment of Mitford medical school and hospital at Dhaka in the early $20^{\text {th }}$ century. The medical education system inherited the typical features of colonial education which is very much on the traditional pattern: lecture based, teacher centered, discipline based, examination oriented and hospital based. Before 1988 there was no formal medical curriculum except a syllabus which was published by Bangladesh medical \& Dental council ${ }^{1}$. The national undergraduate medical curriculum adopted in medical colleges of Bangladesh was first developed in 1988 through Centre for Medical Education (CME) and supported by UNDP and $\mathrm{WHO}^{2}$. The undergraduate medical curriculum followed in the medical colleges was developed with an aim to produce community oriented doctors who will be able to provide essential primary health care to the community. But evaluation by the UNDP and Godfrey et al revealed that it was neither community oriented nor competency based and there were scope for much improvement ${ }^{3}$.

During the last few decades many authorities like World Federation for medical Education (WFME) and General Medical Council (GMC) highlighted the need for reorientation of medical education and suggested for such changes ${ }^{4}$. Various innovations and trends which have been undertaken globally as strategies include education for capability to reduce information overload, community oriented medical education, problem based learning, early

\footnotetext{
1. Professor, Department of Pathology

Armed forces Medical College Dhaka Cantonment, Dhaka.

2. Professor, Curriculum Development \& Evaluation Centre for Medical Education, Mohakhali, Dhaka.
}

Address of correspondence:

Brig Gen Dr. Md. Mohibur Rahman

Professor, Department of Pathology, Armed forces Medical College

Dhaka- 1206, Bangladesh

Email: muhibdr@gmail.com patient contact and integrated learning ${ }^{5}$.

In the light of above situation, the new undergraduate medical curriculum 2002 was developed with the initiative of Further Improvement of Medical Colleges (FIMC) project and WHO by Centre or Medical Education (CME $)^{6}$.

This undergraduate medical curriculum 2002 has three phases; namely Phase I, Phase II and Phase III. During the first one and half year (Phase I) students were taught about Anatomy, Physiology \& Biochemistry and introductory chapters of Community Medicine. During the next two years (Phase II) students learned about five para-clinical subjects such as Community Medicine, Forensic Medicine, Pathology, Pharmacology \& Toxicology and Microbiology along with the clinical subjects like Medicine \& allied subjects, Surgery \& allied subjects and Gynaecology \& Obstetrics. During this time students were attached to the wards for their clinical training. In last one \& half years (Phase III) students continued to learn about Medicine, Surgery \& Gynaecology. One notable findings of this curriculum was that students learned about all para-clinical subjects together ${ }^{3}$. In 2012 Bangladesh Medical and Dental Council (BMDC) introduced the current undergraduate MBBS curriculum with some modifications of previous one. In present curriculum, the total course is divided into four phases. Keeping the subjects same, phase III has been renamed as Phase IV and Phase I as before. Phase II of previous curriculum has been rearranged into two with Community Medicine \& Forensic Medicine in Phase II and Pathology, Pharmacology \& Toxicology and Microbiology in Phase III. During Phase II, students also have schedule classes for clinical subjects such as Medicine \&allied subjects and Surgery \& allied subjects.

In the meantime a considerable number of students have followed this curriculum. The present study was conducted to collect the views of teachers and students regarding the distribution of subjects in Phase II and Phase III of MBBS course.

Bangladesh Journal of Medical Education 2019;10(2):19-22. (C) 2019 Rahman et al., publisher and licensee Association for Medical Education. This is an Open Access article which permits unrestricted non-commercial use, provided the original work is properly cited. 


\section{Methodology}

This study was conducted among the teachers and students of 12 public \& Non-Government medical colleges of Bangladesh from July 2017 to Apr 2018. Purposive sampling technique was adopted to collect data. Data was collected by using self-administered semi-structured questionnaire. The questionnaires were distributed to the students of Phase II, Phase III and Phase IV at the end of their lecture classes and were collected with the responses. Data from the teachers were collected by personal contact according to their convenience. Data were computed and processed using SPSS 23.

\section{Results}

A total of 1090 and 107 questionnaires were distributed among the students and teachers respectively. Among them 991(90.83\%) students and 91(85\%) teachers responded.

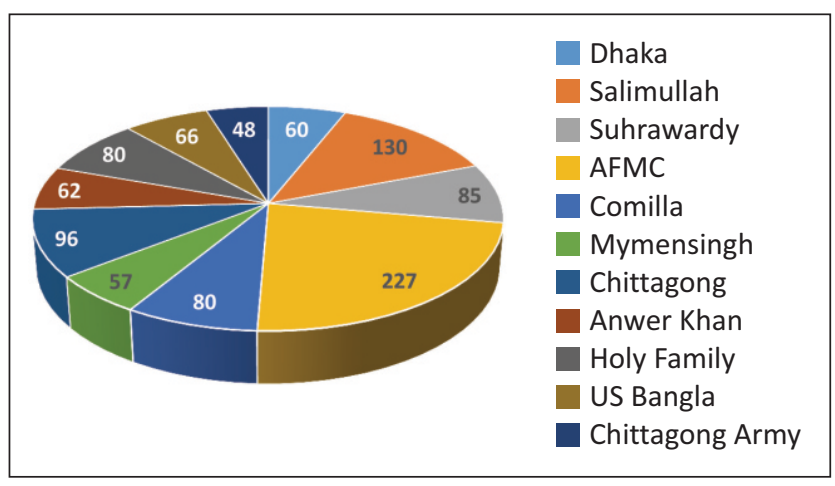

Figure 1: Distribution of students by their institutes ( $\mathrm{n}=991$

Figure 1 shows that out of 991 students, 227 were from AFMC, 130 were from Sir Salimullah Medical College, 85 were from Shaheed Suhrawardy Medical College and 80 were from Dhaka Medical College.

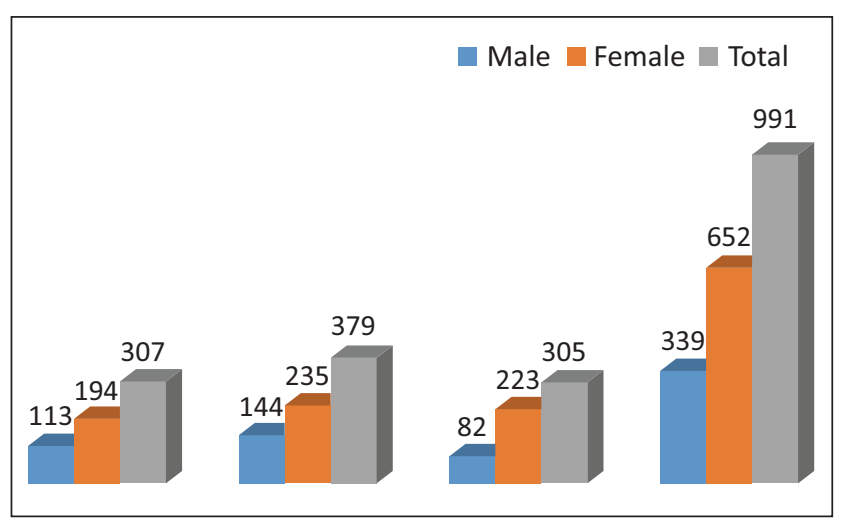

Figure 2: Distribution of students by gender in different Phases $(\mathrm{n}=991)$

Figure 2 shows that out of 991 students, 307 were from Phase II, 379 were from Phase III and 305 were from Phase IV of different medical colleges.

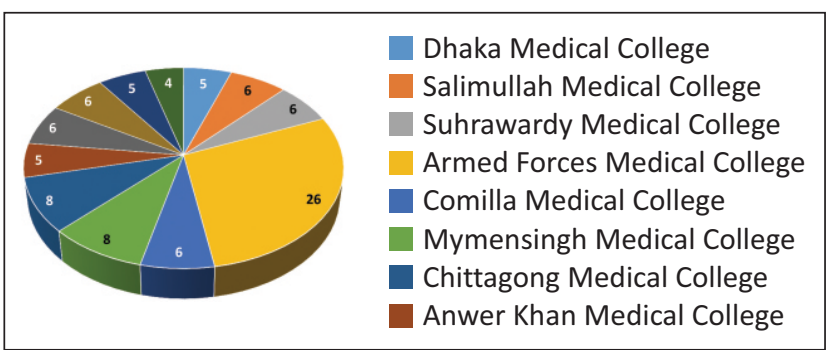

Figure 3: Distribution of teachers by their institutes $(\mathrm{n}=91)$

Figure 3 shows that out of 91 teachers, 26 were from AFMC, 8 from Mymensingh Medical College and Chittagong Medical College.

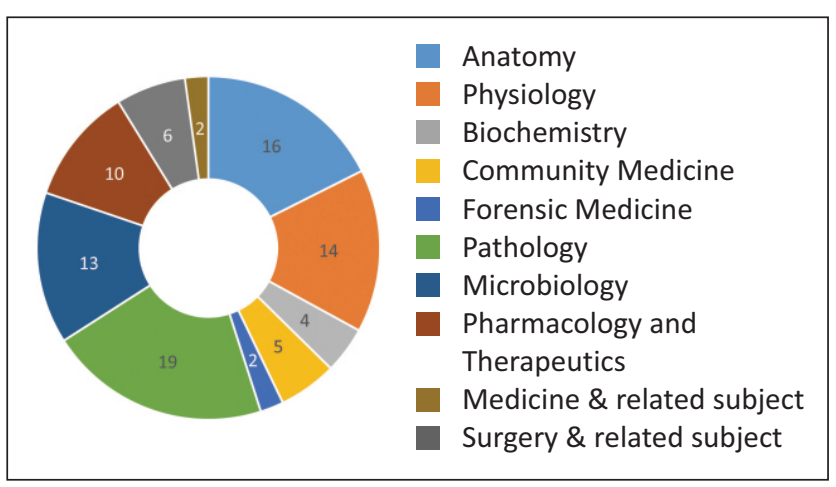

Figure 4: Distribution of teachers by their speciality $(n=91)$

Figure 4 shows that out of 91 teachers, 19 were from Pathology, 16 were from Anatomy, 14 were from Physiology and 13 were from Microbiology Department.

Table 1: Distribution of the respondents by their opinion regarding the sequential distribution of subjects in Phase II \& Phase III of MBBS course

\begin{tabular}{lccc}
\hline Respondent & $\begin{array}{c}\text { Properly } \\
\text { arranged }\end{array}$ & $\begin{array}{c}\text { Need } \\
\text { rearrangement }\end{array}$ & $\begin{array}{c}\text { Statistical } \\
\text { inference }\end{array}$ \\
\hline Student $(\mathrm{n}=991)$ & $9.7 \%$ & $90.3 \%$ & $\chi^{2}=0.539$, \\
Teacher $(\mathrm{n}=91)$ & $12.1 \%$ & $87.9 \%$ & $\mathrm{df}=1$ \\
Total $(\mathrm{n}=1082)$ & $9.9 \%$ & $90.1 \%$ & $\mathrm{P}=0.463$ \\
\hline
\end{tabular}

Table 1 shows that $90.1 \%$ of the respondents opined for need rearrangement regarding the sequential distribution of subjects in Phase II \& Phase III of MBBS course. This opinion was not statistically different among the students and teachers $(\mathrm{P}=0.463)$. 
Table 2: Distribution of the respondents by their phases and opinion regarding the sequential distribution of subjects in Phase II \& Phase III of MBBS course

\begin{tabular}{lccc}
\hline Respondent & $\begin{array}{c}\text { Properly } \\
\text { arranged }\end{array}$ & $\begin{array}{c}\text { Need } \\
\text { rearrangement }\end{array}$ & $\begin{array}{c}\text { Statistical } \\
\text { inference }\end{array}$ \\
\hline Phase II $(\mathrm{n}=307)$ & $12.7 \%$ & $87.3 \%$ & $\chi^{2}=9.417$ \\
Phase III $(\mathrm{n}=379)$ & $10.6 \%$ & $89.4 \%$ & $\mathrm{df}=2$ \\
Phase IV $(\mathrm{n}=305)$ & $5.6 \%$ & $94.4 \%$ & \\
Total $(\mathrm{n}=991)$ & $9.7 \%$ & $90.3 \%$ & $\mathrm{P}=0.009$ \\
\hline
\end{tabular}

Table 2 shows that $90.3 \%$ of the respondents opined for need rearrangement regarding the sequential distribution of subjects in Phase II \& Phase III of MBBS course. This opinion was not statistically significant among the different phases of students $(\mathrm{P}=0.009)$.

Table 3: Distribution of the respondents according to their choice of subjects in phase II of MBBS course

\begin{tabular}{lcc}
\hline \multirow{2}{*}{ Subjects } & \multicolumn{2}{c}{ Respondents' categories } \\
\cline { 2 - 3 } & Student $\mathbf{n}(\%)$ & Teacher n (\%) \\
\hline Pathology & $472(19.1)$ & $51(24.8)$ \\
Microbiology & $363(14.7)$ & $28(13.6)$ \\
Pharmacology & $242(9.8)$ & $29(14.1)$ \\
\&Therapeutics & & \\
Community Medicine & $722(29.2)$ & $54(26.2)$ \\
Forensic Medicine & $671(27.2)$ & $44(21.4)$ \\
Total & $2470(100)$ & $206(100)$ \\
\hline
\end{tabular}

Table 3 shows that out of the respondent students, $29.2 \%$ were in favor of Community Medicine, $27.2 \%$ were in favor of Forensic Medicine and 19.1\% were in favor of Pathology in their Phase II course. On the other hand out of the respondent teachers, $26.2 \%$ were in favor of Community Medicine, 21.2\% were in favor of Forensic Medicine and $24.8 \%$ were in favor of Pathology in their Phase II course.

Table 4: Distribution of the respondents according to their choice of subjects in phase III of MBBS cours

\begin{tabular}{lcc}
\hline & \multicolumn{2}{c}{ Respondents' categories } \\
\cline { 2 - 3 } Subjects & Student n (\%) & Teacher n (\%) \\
\hline Pathology & $424(21.1)$ & $29(14.9)$ \\
Microbiology & $533(26.5)$ & $52(26.8)$ \\
Pharmacology & $656(32.6)$ & $51(26.3)$ \\
$\&$ Therapeutics & & \\
Community Medicine & $176(8.7)$ & $27(13.9)$ \\
Forensic Medicine & $223(11.1)$ & $25(18)$ \\
Total & $2012(100)$ & $194(100)$ \\
\hline & & $*$ Multiple response
\end{tabular}

Table 4 shows that out of the student respondents $32.6 \%$ were in favor of Pharmacology and Therapeutics, 26.5\% were in favor of Microbiology and $21.1 \%$ were in favor of Pathology in their Phase III course. On the other hand out of the respondent teachers, $26.8 \%$ were in favor of Microbiology, 26.3\% were in favor of Pharmacology \& Therapeutics and $18 \%$ were in favor of Forensic Medicine in their Phase III course.

\section{Discussion}

In the undergraduate medical curriculum 2012, Phase I is 1.5 years, Phase II \& Phase III are 1 year for each and Phase IV is 1.5 years duration ${ }^{6}$. This frame work provides opportunity for early clinical exposure by the students of Phase II. This early exposure of students with clinical cases is consistent to the recommendation of Tomorrow's Doctors of the General Medical Council (GMC) of Uk ${ }^{5}$.

In the previous undergraduate medical curriculum 2002, the MBBS course was conducted in 3 phases namely Phase I, Phase II and Phase III. All the para-clinical subjects such as Community Medicine, Forensic Medicine, Pathology, Pharmacology \& Therapeutics and Microbiology were taught in Phase II in 2 years duration. Considering the students' discomfort, anxiety, tension and load of five subjects at a time, the Phase II of previous curriculum has been rearranged as Phase II and Phase III in 2012 by Bangladesh Medical \& Dental Council. According to this curriculum, Community Medicine \& Forensic Medicine are taught in Phase II and Pathology, Pharmacology \& Toxicology and Microbiology are taught in Phase III. Now considering the approach and understanding of clinical subjects by the students of Phase II a study has been conducted to collect views from students and teachers.

In our study out of 991 students and 91 teachers, 895(90.3\%) students and $80(87.9 \%)$ teachers opined for rearrangement of subjects in Phase II and Phase III of MBBS course (Table 1). Table 3 revealed that students of senior class (94.4\%) were more in favor of rearrangement of subjects than junior class (87.3\%). According to the present MBBS curriculum students get exposure of clinical subjects from the beginning of Phase II but there are no allocation of classes for pathology, Pharmacology \& Toxicology and Microbiology in this Phase. Some preliminary knowledge of the above para-clinical subjects are is the requirement to understand the clinical subjects. Probably for that reason a huge number of participants opined in favor rearrangement of subjects among the Phase II \& Phase III (Table 1).

Regarding the distribution of subjects, our study revealed that $29.2 \%$ students opined for Community Medicine, $27.2 \%$ opined for Forensic Medicine and $19.1 \%$ opined for Pathology in Phase II of the MBBS course. On the other hand, 26.2\% teachers proposed for Community Medicine, $21.4 \%$ proposed for Forensic Medicine and $24.8 \%$ proposed for Pathology in Phase II of MBBS course. In one study, Ullah MA showed that out of 396 students, majority (62.6\%) suggested for Pharmacology \& Toxicology and Community

Bangladesh Journal of Medical Education 2019;10(2):19-22 
Medicine in Phase II and Forensic Medicine, Pathology and Microbiology in Phase III. On the other hand more than $80 \%$ teachers suggested Pharmacology \& Toxicology and Forensic Medicine in Phase II and Community Medicine, Pathology and Microbiology in Phase III. This study findings are quite different from the present study. Ullah et al. conducted the study among the students and teachers before the implementation of 2012 MBBS curriculum but our study was conducted 4 years after the implementation of present curriculum and our findings are the reflection of the teaching-learning experiences by the teachers and students.

According to MBBS curriculum of Pakistan students get exposure of clinical cases after the $1^{\text {st }}$ professional examination by attending the lecture classes and ward placement. At the same time they used to learn Pharmacology, Forensic Medicine, Pathology and microbiology .

In India, the MBBS course has been divided in 3 phases. Students were taught basic subjects in Phase I. They were devoted to Pathology, Community Medicine, Forensic Medicine, Pharmacology and Microbiology in Phase II. During this Phase clinical subjects were taught concurrently'.

In Sri Lanka basic subjects are taught in year 1 and 2 of their MBBS course. They used to learn Pathology, Microbiology, Pharmacology and Community Medicine in year 3 and year 4. Teaching of clinical class begins from the year 3 and continued up to year $5^{10}$.

MBBS curriculum of three neighboring countries (Pakistan, India and Sri Lanka) reveals that Pathology, Microbiology, Pharmacology and Community Medicine are taught at the beginning of clinical classes. In this study students and teachers suggested for Community Medicine, Forensic Medicine and Pathology at the beginning of the clinical classes which has some similarity with the neighboring countries.

\section{Conclusion}

Para-clinical subjects play a bridging role between the preclinical and clinical subjects. Without the knowledge of para-clinical subjects it is difficult to understand the clinical subjects. This study showed opinion of students and teachers regarding the distribution of subjects in Phase II and Phase III of MBBS course. Majority of the teachers and students proposed the subject Pathology to be included in Phase II with the existing subjects of Community Medicine and Forensic Medicine. This study recommends a more extensive survey and compilation of expert opinion during the future curriculum review.

\section{Acknowledgement}

We are thankful to all those students and teachers from whom we have collected data for the study. We would also like to express our gratitude to Centre for Medical Education for allowing us to conduct the study.

\section{References}

1. Majumder MAA. Bangladesh Medical Journal 2003; 32:37-39.

2. Hussain MM, Tlukder HK, Moazzem M, Rashid A, Hanif A, Nargis T. Evaluation of Existing Curriculum (2002) of Undergraduate Medical Education in Bangladesh. Mymensingh Medical Journal 2011;20(2): 226-232.

3. Curriculum for Undergraduate Medical Education in Bangladesh 2002.

4. World Federation for Medical Education. The Edinburgh Declaration. Medical Education 1988; 22: 481-2.

5. GMC, Tomorrow's Doctors, Recommendations on Undergraduate Medical Curriculum, London: General Medical Council, 1993.

6. Curriculum for Undergraduate medical Education in Bangladesh- Updated 2012.

7. Ullah MA, Selimuzzaman ABM, Haque MJ, Sarker GC, Rahman MM. Curriculum for Undergraduate Medical Education in Bangladesh 2012: Reflection of Teachers' and Students' Expectation. Barind Medical College Jpurnal 2016;2(1):23-28.

8. Curriculum of MBBS (Revised 2011), Pakistan Medical \& Dental Council and Higher Education Commission, Islamabad

9. MBBS degree course and Curriculum of Phase I and II Subjects - 2004, Rajiv Ghandhi University of Health Sciences, Karnataka.

10. Curriculum of MBBS course 2016, Faculty of Medicine and Allied Sciences, Rajarata University of Sri-Lanka, Mihintale. 